\title{
The integration of quality management systems in testing laboratories: a practitioner's report
}

\author{
Pieter Dehouck ${ }^{1} \cdot$ Robert Koeber $^{1} \cdot$ Elena Scaravelli $^{1} \cdot$ Hendrik Emons $^{1}$
}

Received: 4 September 2018 / Accepted: 19 November 2018 / Published online: 28 December 2018

(c) The Author(s) 2018

\begin{abstract}
When routine laboratories merge or are taken over by larger entities, their quality management systems usually need to be integrated. In many laboratories, quality management systems according to ISO/IEC 17025 are in place. The integration of the quality management systems is often advantageous in terms of efficiency of operations, reduction in number of processes and consequently amount of quality documentation. However, a number of practical problems, some of them hard to overcome, may be encountered. Examples are: how to deal with multi-site activities showing technical and/or cultural differences, how to merge historically different ways of working and how to overcome psychological resistance to change from laboratory staff. This paper demonstrates a way of working used in our organisation to integrate successfully the quality management systems of several laboratories under one quality management system. The laboratories were located in two different countries (Belgium and Italy) and had activities under ISO/IEC 17025, ISO/IEC 17043 and ISO Guide 34 accreditation. Involvement of the laboratory staff was essential for obtaining a fast and efficient integration.
\end{abstract}

Keywords Accreditation · Integration · Quality management system $\cdot$ Testing laboratory

\section{Introduction}

Analytical laboratories, just like any other organisation, are subject to change. Small laboratories merge with other laboratories or are taken over by large entities. Nowadays, these routine laboratories are accredited in many cases according to the ISO/IEC 17025 standard [1]. Accreditation allows testing laboratories to demonstrate that they operate competently and generate valid results. As a prerequisite, these laboratories have a quality management system in line with this accreditation standard. It implies that the laboratory has developed documented procedures for its processes covered by the standard. When laboratories merge, their quality management systems usually need to be merged as well for a number of reasons:

1. The merged laboratory may like to be accredited by only one accreditation body. This is important in case the laboratories are located in different countries, since

Pieter Dehouck

Pieter.Dehouck@ec.europa.eu

1 European Commission, Joint Research Centre (JRC), Geel, Belgium accreditation is handled at a national level. In case similar activities are carried out at the different sites, it is advantageous for the laboratory that these are assessed by the same auditors and technical experts. Another reason why the laboratory may like to engage only one accreditation body is to reduce costs. The total cost for maintaining the accreditation is usually lower when the laboratory activities are accredited by only one accreditation body due to lower dossier costs and less time needed for auditing the general aspects of the quality system.

2. The merged laboratory may have the wish to merge the scopes of accreditation. Having one extended scope of accreditation may give a competitive advantage to the laboratory. Similar accredited activities existing in two or more sites can also be centralised in one site since these activities remain described in the merged scope.

The above points 1 and 2 can be obtained with a multi-site accreditation, but require that the merged laboratory can prove to the accreditation body that its quality management system is managed in an integrated manner.

3. Integrating the quality management systems usually increases the efficiency of the operations by using 
shared resources. Examples are: a reduced total number of internal audits, an extended pool of internal auditors both reducing the burden per capita, a reduced number of management review meetings, a harmonised approach towards training and authorisation of staff, a harmonised approach towards subcontracting of activities and evaluation of suppliers, and the use of shared tools for document control, sample registration and creation of test reports. Moreover, different ways of working can be compared during the merge in order to select the most efficient one.

4. As a result of a reduced number of duplicated processes, the total number of quality documents decreases by avoiding unnecessary duplication of quality documents. Also the total number of produced quality records (e.g. internal audit reports, management review reports) decreases.

5. The merged quality management system allows a more centralised management of the accredited activities.

Despite the listed advantages of integrating the quality management systems, a number of practical obstacles may be experienced that can hamper this integration process:

1. When the laboratory sites are located in different countries, different accreditation bodies were responsible for assessing the different quality management systems before the merge. Although these accreditation bodies assess against the same quality standard, different interpretations of the standard may occur. Even though this has improved in recent years as accreditation bodies are organised at regional level, e.g. under the European co-operation for Accreditation (EA), and at global level via the International Laboratory Accreditation Cooperation (ILAC) and the International Accreditation Forum (IAF), different interpretations still exist. As a result, the standard will be implemented in a slightly different way in laboratories located in different countries.

2. The structure of a quality management system is usually historically grown and can therefore differ significantly between different laboratories. Not only the structure of the quality management system, but also the nomenclature, the identification and the structure of the quality documentation may differ. One example of different nomenclatures is the term standard operating procedures in one laboratory, which may be called standard procedures, work(ing) procedures, procedures, work(ing) instructions, instructions or anything else in another laboratory. This different nomenclature may be linked to a different structure in quality documentation. Harmonising different structures of quality documentation and different structures of quality management systems can be very labour-intensive.
3. The tools used to manage certain laboratory processes may be different, e.g. the document control software, sample registration and test reporting tools like Laboratory Information Management System (LIMS) or tools to monitor environmental conditions. Harmonising these may result in serious information technology (IT) challenges.

4. Laboratory staff is often used to follow certain processes for years. As it is the natural psychological and physiological reaction of humans to be sceptical of changes, there may be a lot of resistance to new, changed processes. This aspect comes on top of any technical aspect. Even when the new integrated process simplifies the life of the laboratory staff, there may be resistance to change certain "habits". This psychological aspect should not be underestimated and will often be harder to overcome than any technical or structural aspect.

This paper describes an integration exercise carried out from July 2016 till June 2017 at the European Commission's Joint Research Centre (JRC). Following a reorganisation, three laboratories hosting in total six European Union Reference Laboratories were merged among others within the newly created Food and Feed Compliance Unit. The three laboratories with accredited activities were located in Geel (Belgium, one laboratory) and Ispra (Italy, two laboratories), and their activities were under accreditation by the Belgian accreditation body BELAC and the Italian accreditation body Accredia, respectively. The laboratories had each of their own quality management system in line with ISO/ IEC 17025:2005, ISO/IEC 17043:2010 and ISO Guide 34 (nowadays replaced by ISO 17034:2016) [2-5]. This paper describes how the quality management systems were integrated and how all accredited activities were brought under one BELAC multi-site accreditation.

\section{Action plan}

Before starting the integration exercise, an action plan was drafted. This plan was also shared with the Belgian accreditation body. The actions were distributed in seven categories according to their origin (Table 1):

1. Accreditation: Actions to safeguard the accreditation status of activities of the merged laboratories.

2. Quality management system (QMS) structure: Adaptation of the QMS structure to the new organisational structure of the merged laboratory.

3. QMS processes: Listing the processes currently in place in the three laboratories, comparing these processes by making reference to the relevant quality documents (pro- 
Table 1 Example of an action plan with the respective action number, the origin of the action, a general description of the action, concrete action points and other aspects

\begin{tabular}{|c|c|c|c|c|}
\hline \multicolumn{5}{|c|}{ Action plan example } \\
\hline Action no. & Origin & Description & Actions & Other \\
\hline 1 & Accreditation & Safeguard the accreditation status & $\begin{array}{l}\text { E.g., contact national accreditation bodies } \\
\text { E.g., update of accreditation certificates }\end{array}$ & $\begin{array}{l}\text { Deadline } \\
\text { Staff } \\
\text { Status }\end{array}$ \\
\hline 2 & QMS structure & $\begin{array}{l}\text { Adaptation of the QMS structure to the new } \\
\text { organisational structure of the merged labora- } \\
\text { tory }\end{array}$ & $\begin{array}{l}\text { E.g., update of organigram } \\
\text { E.g., define shared QMS responsibilities } \\
\text { E.g., appointment of staff }\end{array}$ & $\begin{array}{l}\text { Deadline } \\
\text { Staff } \\
\text { Status }\end{array}$ \\
\hline 3 & QMS processes & Listing, comparing, harmonising & $\begin{array}{l}\text { E.g., list the relevant QMS-related processes } \\
\text { E.g., compare relevant QMS-related processes } \\
\text { E.g., harmonise relevant QMS-related processes }\end{array}$ & $\begin{array}{l}\text { Deadline } \\
\text { Staff } \\
\text { Status }\end{array}$ \\
\hline 4 & QMS documentation & $\begin{array}{l}\text { Update, revision and merge of the quality } \\
\text { documentation }\end{array}$ & $\begin{array}{l}\text { E.g., compare nomenclature and structure } \\
\text { E.g., harmonise nomenclature and structure } \\
\text { E.g., revise and harmonise quality documenta- } \\
\text { tion } \\
\text { E.g., make quality documentation obsolete } \\
\text { where needed }\end{array}$ & $\begin{array}{l}\text { Deadline } \\
\text { Staff } \\
\text { Status }\end{array}$ \\
\hline 5 & Personnel & Responsibilities, appointments and trainings & $\begin{array}{l}\text { E.g., define shared QMS responsibilities } \\
\text { E.g., appointment of staff } \\
\text { E.g., training of staff }\end{array}$ & $\begin{array}{l}\text { Deadline } \\
\text { Staff } \\
\text { Status }\end{array}$ \\
\hline 6 & Internal audits & $\begin{array}{l}\text { Maintain existing schedules + develop new } \\
\text { schedule }\end{array}$ & $\begin{array}{l}\text { E.g., finalise existing internal audit schedules } \\
\text { E.g., develop internal audit schedule for merged } \\
\text { laboratory }\end{array}$ & $\begin{array}{l}\text { Deadline } \\
\text { Staff } \\
\text { Status }\end{array}$ \\
\hline 7 & Resources & Make available all resources to manage QMS & $\begin{array}{l}\text { E.g., ensure a proper folder structure to store } \\
\text { documents } \\
\text { E.g., ensure shared IT tools for document con- } \\
\text { trol, sample registration and reporting }\end{array}$ & $\begin{array}{l}\text { Deadline } \\
\text { Staff } \\
\text { Status }\end{array}$ \\
\hline
\end{tabular}

cedures/working instructions) and harmonising these processes between the three laboratories.

4. QMS documentation: Comparison and harmonisation of the nomenclature and structure used for the quality documentation in the three laboratories. Update, revision and merge of the quality documentation in line with the new organisational structure and with the harmonised processes. The merge of documents also leads to the obsolescence of duplicated documents.

5. Personnel: Defining responsibilities relevant to the QMS, appointing the relevant personnel, organisation of trainings for personnel holding functions relevant to the QMS and organisation of general trainings to all staff on the harmonised/updated/revised processes and quality documents.

6. Internal audits: Ensuring that the existing internal audit schedules are maintained and development of an internal audit schedule for the merged laboratory.

7. Resources: Ensuring that all resources (e.g. IT resources) are available in order to manage the QMS of the merged laboratory.

The general actions were split up into concrete points of action which were assigned to the relevant staff with clear deadlines. The status of the action plan had been regularly reviewed and updated in order to ensure deadlines were respected.

\section{Harmonisation of structure and nomenclature of the quality documentation}

Before harmonising the processes, the structure and nomenclature of the quality documentation were harmonised. Table 2 lists the different nomenclature used by the three laboratories and the harmonised nomenclature. It was observed that the same nomenclature in different laboratories could have a different meaning. For instance, the standard operating procedures in laboratory 1 were considered working instructions for laboratory 2 , while the standard operating procedures in laboratory 2 were considered procedures for laboratory 3 , depending on the content of the respective documents. Harmonising the nomenclature of the quality documentation was fundamental to facilitate the comparison and harmonisation of the processes at a later stage. At the beginning of the integration exercise, a conversion table was used to link the old and new nomenclature. 
Table 2 Harmonisation of quality documentation nomenclature between the three laboratories with the harmonised nomenclature and the nomenclature that was in use in laboratories 1,2 and 3

\begin{tabular}{llll}
\hline Harmonised nomenclature & Laboratory 1 & Laboratory 2 & Laboratory 3 \\
\hline Quality manual & Quality manual & Quality manual & Procedures \\
Procedures & Managing procedures & General procedures & Work instructions \\
& Working operating procedures & Standard operating procedures & Forms \\
Work instructions & Standard operating procedures & Working instructions & Forms \\
Forms & Forms & Templates & \\
& & & \\
\hline
\end{tabular}

\section{Harmonisation of processes}

One of the most difficult aspects when merging the quality management systems of laboratories is the harmonisation of the processes. In order to have the involvement of all staff, working groups with representatives of the three laboratories were created. The processes that were relevant for the ISO/IEC 17025, ISO/IEC 17043 and ISO Guide 34 accreditations were listed and grouped where possible

Table 3 Listing of processes relevant for the accreditation standards and attribution of the integration of these processes to the working groups and quality managers

\begin{tabular}{|c|c|c|c|}
\hline ISO/IEC 17025:2005 & ISO Guide 34 & ISO/IEC 17043:2010 & Working groups \\
\hline 4 Management requirements & $\begin{array}{l}4 \text { Organisation and management } \\
\text { requirements }\end{array}$ & 5 Management requirements & Quality managers \\
\hline 4.03 Document control & 4.3 Document and information control & 5.3 Document control & Working group 1 \\
\hline 4.13 Control of records & 4.13 Records & 5.13 Control of records & \\
\hline $\begin{array}{l}\text { 4.04 Review of requests, tenders and } \\
\text { contracts }\end{array}$ & 4.4 Request, tender and contract reviews & $\begin{array}{l}5.4 \text { Review of requests, tenders and } \\
\text { contracts }\end{array}$ & Working group 2 \\
\hline
\end{tabular}

5.08 Handling of test and calibration

items

5.09 Assuring the quality of test and

calibration results

5.10 Reporting the results

4.06 Purchasing services and supplies

4.06.4 Evaluation of suppliers

4.7 Service to the customer

4.08 Management of complaints

4.09 Management of non-conformities

4.10 Improvement

4.11 Corrective action

4.12 Preventive action

4.14 Internal audits

4.15 Management reviews

5.02 Personnel

5.03 Accommodation and environmental conditions

5.05 Equipment

4.6 Procurement of services and supplies

4.7 Customer service

4.8 Complaints

4.9 Control of non-conforming work and/or reference materials

5.06.3 Reference standards and reference materials

5.04.5 Validation of methods

5.04.6 Estimation of uncertainty of measurement
4.8 Reports

5.6 Purchasing services and supplies Working group 3

5.7 Service to the customer

5.8 Complaints and appeals

5.9 Control of non-conforming work

Quality managers

Working group 4

5.14 Internal audits

5.15 Management reviews

4.2 Personnel

4.3 Equipment, accommodation and environment

4.3 Equipment, accommodation and environment

Quality managers Quality managers Working group 5 Working group 6

4.14 Internal audits
4.15 Management reviews
5.2 Personnel
5.6 Accommodation and environmental
conditions
5.10 Measuring equipment

5.9.2 Validation of methods
Working group 7

PT organisation according to ISO/IEC 17043 
(Table 3). General QMS processes were integrated by the quality managers while the other processes were assigned to the working groups. The task of the working groups was divided in two parts: (1) a screening phase with a comparison of the processes in the three laboratories and (2) a development phase with the preparation of draft procedures describing the integrated process(es). For each phase, the working group was given about two months of time, and after each phase a consultation meeting with the quality managers was organised. During the screening phase, the working groups have looked to the quality documentation available in the three laboratories describing the respective process(es). The working groups compared the different ways of working in terms of efficiency, simplicity, tools used, easiness to integrate, etc. Based on this screening, the members of each working group agreed on a proposal for integration. This proposal was discussed with the quality managers before starting the development phase. In the development phase, the working groups prepared the draft procedure(s) describing the integrated process(es). This draft procedure was often based on existing quality documentation in one of the laboratories. Sometimes it had to be completely newly developed. At the end of the development phase, the draft procedures were discussed with the quality managers.

The approach with working groups, which could be called a "bottom-up approach", with the direct involvement of laboratory staff in the integration of the processes had a number of advantages:

1. Less time: As the task of integrating all processes and related quality documents was distributed over a larger number of staff, progress was made faster and simultaneously for different processes. The integration of all processes was finalised in about 6 months.

2. Less resistance: As all laboratories were represented in each working group, integrated processes were accepted more easily by all staff. As laboratory staff was directly involved, the impression that integrated processes were "imposed" on staff could be avoided.

3. More engagement: Staff was more involved in the full process of integrating the quality management systems and understood better the difficulties of this integration process.

4. Better and faster implementation: The direct involvement of laboratory staff helped in the proper and efficient implementation of the integrated processes.

\section{Harmonisation of tools}

Together with the harmonisation of processes, some of the tools used to manage these processes needed to be harmonised as well. One example was the software tool for document control which was different in the three laboratories. One laboratory used a commercial software tool, while the other two laboratories used a home-made software tool. During the screening of the document control process, the working group concluded that the home-made software tool could hardly be extended to the three laboratories. Moreover, the process with the home-made software tool was found to be more labour-intensive in terms of maintenance. Therefore, it was decided to use the commercial software tool, meaning that a large number of documents of the two laboratories needed to be transferred from their home-made tool to the commercial software tool. At the time of the transfer, the identification codes of the documents were adapted and harmonised. This labour-intensive task was somewhat simplified by the fact that a number of documents were made obsolete as a result of the integration exercise performed by the working groups.

\section{Harmonisation of responsibilities}

The merge of laboratories resulted in a changed QMS structure with an updated laboratory organigram. Because of this, a number of new and harmonised QMS responsibilities have to be assigned to staff. These responsibilities were both in management positions (e.g. technical managers, quality managers, laboratory managers) and in more technical positions (e.g. balance coordinators, temperature and humidity responsibilities, proficiency test coordinators). Harmonisation in the management positions was of high importance since it was directly linked to the new organigram of the merged laboratory. The assignment of these responsibilities to staff was performed by top management and involved a proper and documented training of staff who was new to a function.

\section{Other integration aspects}

The internal audit schedules which were created before the merge of the laboratories were slightly modified in line with the new structure of the merged laboratory. It was important to ensure the completion of these internal audit schedules as planned for the running year. For the following year, a new integrated schedule was developed with 
internal audits distributed over the two sites. While the integrated processes could be audited across sites, the need for some site-specific internal audits was also obvious.

Another aspect of the integration was the development of a proper integrated folder structure in order to store QMSrelated records like internal audit reports, management review records, non-conformities, complaints. The folder structure needed the correct access rights for all staff on the two sites. The set-up of this folder structure required the help of the IT department. In the same line, all staff was given access to the software tools.

The training of staff in the newly integrated processes was a final and important aspect of the integration exercise. Proper training was important in order to ensure a full and correct implementation of the integrated processes. Therefore, a number of training sessions were organised, each of them focussing on different processes. Videoconference tools helped to provide these trainings across sites at the same time. More personalised trainings were given to staff taking up specific functions in the integrated quality management system. All these trainings were documented in line with the process for the management of personnel.

Another practical issue faced during the integration across sites was the interaction between the quality managers located at the Geel site and staff working at the Ispra site. Although a number of communication tools including videoconference facilities were available, a quality contact point was appointed for the Ispra site in order to facilitate the communication with the quality managers and see proper implementation of the quality management system at the Ispra site.

\section{BELAC assessment of the integrated activities}

The integrated quality management system of the merged laboratory was reviewed during a 7-day assessment by the Belgian accreditation body BELAC. The external BELAC assessors visited both sites in Geel and Ispra and checked if the processes had been properly integrated and implemented accordingly. Technical assessments of all accredited activities at the Geel and Ispra site took place as well. The external audits were passed successfully, and the assessors highlighted the competence of staff, the fact that the transition towards the integrated quality management system was finalised in less than 1 year following the reorganisation, the good interaction between management and staff and the present quality culture. The set-up of the working groups with involvement of staff in the integration process contributed a lot to this positive outcome. Following the successful BELAC assessment, the merged laboratory obtained a BELAC multi-site accreditation including all accredited activities at the Geel and Ispra sites. At that moment, the accreditations of the Ispra site activities with the Italian accreditation body were stopped as agreed beforehand with the Belgian and Italian accreditation bodies.

\section{Conclusions}

The merging of laboratories may require the integration of the corresponding quality management systems. This paper illustrated how the quality management systems of different laboratories have been integrated while maintaining the accreditation status according to ISO/IEC 17025, ISO/ IEC 17043 and ISO Guide 34. A bottom-up approach has strongly supported staff involvement in the integration process and contributed to a fast, efficient and proper integration of the relevant processes.

Open Access This article is distributed under the terms of the Creative Commons Attribution 4.0 International License (http://creativeco mmons.org/licenses/by/4.0/), which permits unrestricted use, distribution, and reproduction in any medium, provided you give appropriate credit to the original author(s) and the source, provide a link to the Creative Commons license, and indicate if changes were made.

\section{References}

1. International Organization for Standardization (2017) ISO/IEC 17025 general requirements for the competence of testing and calibration laboratories. https://www.iso.org/standard/66912.html

2. International Organization for Standardization (2005) ISO/IEC 17025 general requirements for the competence of testing and calibration laboratories

3. International Organization for Standardization (2010) ISO 17043 conformity assessment-general requirements for proficiency testing. https://www.iso.org/standard/29366.html

4. International Organization for Standardization (2009) ISO Guide 34 general requirements for the competence of reference material producers

5. International Organization for Standardization (2016) ISO 17034 general requirements for the competence of reference material producers. https://www.iso.org/standard/29357.html 